\title{
ANALISIS PENINGKATAN REGULASI ASPEK TRANSPORTASI PADA PENYELENGGARAAN KAWASAN TRANSIT ORIENTED DEVELOPMENT DI JABODETABEK
}

\author{
Febri Nur Prasetyo*, Anasta Wirawan \\ Fakultas Teknik, Universitas Gadjah Mada, Jl. Grafika Kampus No.2, Senolowo, Sinduadi, Kec. Mlati, Kabupaten \\ Sleman, Daerah Istimewa Yogyakarta, Indonesia 55281 \\ *febri_np@mail.ugm.ac.id
}

\begin{abstract}
ABSTRAK
Pelaksanaan penyelenggaraan kawasan TOD di Jabodetabek tentunya sangat penting untuk menerapkan kebijakan tata ruang yang saling bersinergi dan sinkron dengan kebijakan transportasi. Tetapi sinkronisasi ini tentunya sangat sulit karena kedua sektor tersebut baik di pusat dan di daerah berada di dalam kelembagaan yang berbeda-beda. Oleh karena itu perlu ada skenario kelembagaan agar koordinasi dan sinkronisasi kebijakan ini harus dilakukan. Selain itu adanya insentif dan disinsentif dalam penerapannya dan hubungannya dengan subsidi di sektor transportasi karena kebijakan TOD ini dapat berjalan apabila ada jaringan angkutan umum massal yang terintegrasi serta payung hukum yang kuat. Penelitian ini dimaksudkan sebagai acuan dalam penguatan disisi regulasi dan kelembagaan khususnya Instansi terkait di Jabodetabek. Penelitian yang dilakukan dirancang dengan menggunakan metode yuridis normative yang juga dilengkapi dengan teknis pada sisi transportasi. Adapun peran penguatan regulasi untuk aspek transportasi pada penyelenggaraan TOD Jabodetabek meliputi penerapan mekanisme LVC yang diperkuat dengan penerapan Bentuk insentif dan disinsentif, disisi lain penguatan.
\end{abstract}

Kata kunci: angkutan umum massal, regulasi; tata ruang; TOD; transportasi

\section{ANALYSIS OF IMPROVING THE REGULATION OF TRANSPORTATION ASPECT ON TRANSIT ORIENTED DEVELOPMENT AREA IN JABODETABEK}

\begin{abstract}
The implementation of the TOD area in Jabodetabek, it is very important to implement spatial policies that are mutually synergistic and synchronous with transportation policies. But this synchronization is certainly very difficult because the two sectors, both at the central and regional levels, are in different institutions. Therefore there needs to be an institutional scenario so that this policy coordination and synchronization must be carried out. In addition, there are incentives and disincentives in their application and their relationship with subsidies in the transportation sector because this TOD policy can work if there is an integrated mass public transport network and a strong regulation. This research is intended as a reference in strengthening the regulatory and institutional side, especially related institutions in Jabodetabek. The research to be carried out is designed using normative juridical methods which are also equipped with technical aspects on the transportation side. The role of strengthening regulations for the transportation aspect in the implementation of the Jabodetabek TOD includes the application of the LVC mechanism which is strengthened by the application of incentives and disincentives, on the other hand strengthening.
\end{abstract}

Keywords: land spatial; mass public transport, regulation; TOD; transport

\section{PENDAHULUAN}

Transportasi selalu terkait dengan orang dan koneksivitas yang berada dalam suatu ruang kawasan, seperti sebuah mesin yang bekerja pada sistemnya maka transportasi memerlukan bagian yang tepat untuk berada di tempat yang tepat dan bekerja sama pada saat yang tepat. Dalam hal ini kawasan Jabodetabek dengan 80 juta perjalanan perhari perlu menjadi perhatian khusus dalam mengakomodir pergerakan masayarakat yang sangat massif. Pergerakan masyarakat menggunakan alat transportasi sejatinya perlu diakomodasi dengan system maupun infrastruktur yang terencana dengan baik dan dalam hal ini dapat melalui 
pengembangan suatu Kawasan simpul moda transpotasi yang dapat dikembangkan menjadi suatu Kawasan dengan fungsi beragam/campuran.

Pengembangan Kawasan simpul moda transportasi menjadi Kawasan campuran yang memiliki aksesibilitas tinggi merupakan daya tarik (value creation) juga memberikan solusi dalam mengakomodir pegerakan orang yang begitu masif, dalam hal ini pengembangan tersebut diwujudkan dalam konsep Transit Oriented Development (TOD). TOD berperan penting di dalam pengembangan jaringan angkutan umum untuk menunjang kerangka kebijakan Transport Demand Management (TDM) atau Manajemen Demand Transportasi. Tamin, 2000 menyatakan bahwa dalam menerapkan kebijakan TDM ini tidak dapat di selesaikan dengan hanya melaksanakan satu solusi/ single solution saja . Ada beberapa kombinasi dari kebijakan umum TDM ini yang perlu diimplementasikan secara bersamaan di wilayah perkotaan.

Pada intinya, konsep tersebut bertujuan untuk memberi alternatif dan pemecahan bagi permasalahan pertumbuhan metropolitan yang cenderung pada pola auto oriented development. Dengan membuat fungsi campuran (mixed use) yang kompak dalam jangkauan lima hingga lima belas menit berjalan kaki pada area-area transit, di harapkan di dapatkan beberapa manfaat. Di antaranya, terjadi internalisasi pergerakan antara hunian, perkantoran dan fungsi-fungsi lain dalam sebuah distrik yang tersentralisasi. Akumulasi pola ini pada level regional di harapkan dapat menolong orang untuk menggunakan fasilitas transit ketimbang kendaraan pribadi. Dengan demikian dapat menyelesaikan permasalahan sprawling. berikut adalah beberapa manfaat pengembangan kota dengan TOD: (1)Mengurangi penggunaan kendaraan pribadi di rumah tangga sehingga menurunkan kemacetan, polusi udara, dan emisi gas rumah kaca. (2)Menciptakan komunitas pejalan kaki di dalam masyarakat yang mengakomodasi gaya hidup yang lebih sehat dan aktif. (3)Peningkatan angkutan penumpang transit dan pendapatan daerah dari tarif angkutan. (4)Potensi nilai tambah melalui nilai properti yang meningkat dan atau berkelanjutan sesuai dengan investasi angkutan. (5)Peningkatan akses terhadap pekerjaan dan kesempatan ekonomi bagi masyarakat berpenghasilan rendah dan keluarga. (6)Perluasan mobilitas dengan mengurangi ketergantungan pada kendaraan bermotor pribadi, sehingga bisa mengurangi biaya transportasi.

Pada kawasan sudah terbangun, pengembangan kawasan TOD dapat dilakukan dengan:

a. Pembangunan kembali tanah atau ruang yang sudah terbangun (redevelopment site), yaitu peremajaan kawasan melalui tahapan perancangan kawasan TOD, perubahan struktur dan penambahan fungsi baru selaras dengan pengembangan kawasan TOD serta penataan lingkungan yang dilengkapi fasilitas transit atau fasilitas kawasan TOD dengan ketentuan pemanfaatan ruang sebagaimana diatur dalam pedoman ini. Dalam strategi ini, Pemerintah/pemerintah daerah dapat mengatur penguasaan tanah pada Kawasan TOD melalui konsolidasi tanah, bank tanah serta perangkat penunjang lainnya dengan memperhatikan peraturan perundangan dan kepentingan umum. 


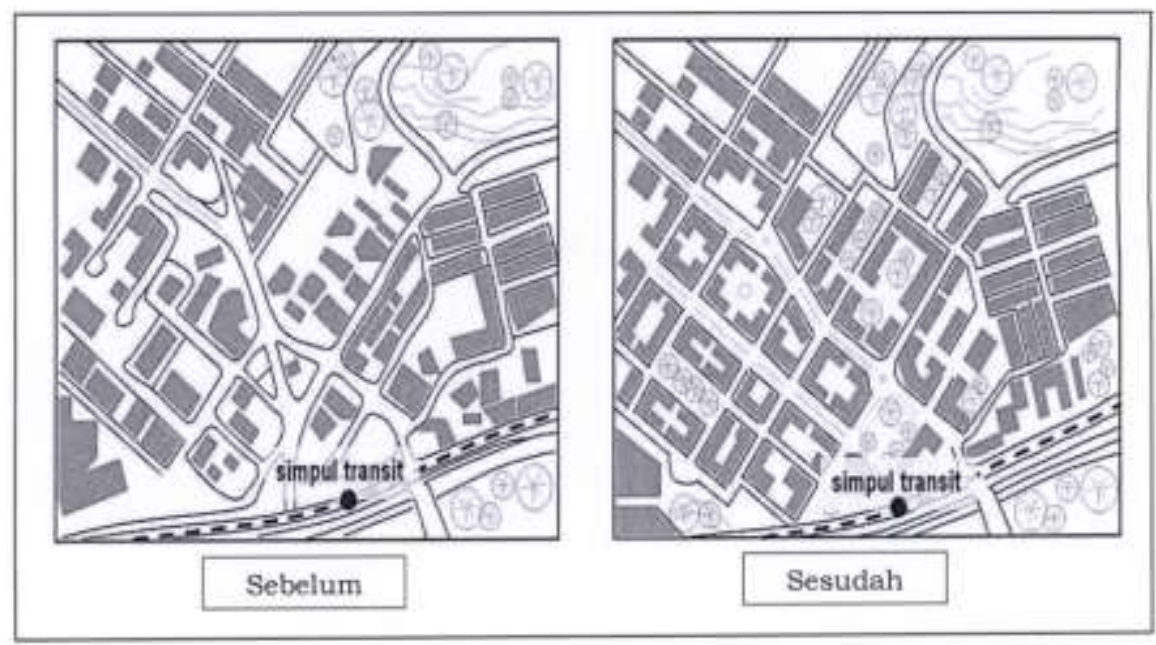

Gambar.1 Pembangunan Kembali Tanah

Sumber: Lampiran Permen ATR BPN No.16 Tahun 2017 tentang Pedoman Pengembangan Kawasan Berorientasi Transit

b. Pembangunan pada tanah kosong di antara tanah terbangun (infill development site), yaitu pengembangan pada tanah kosong/terbengkalai di antara tanah terbangun pada radius pengembangan kawasan TOD Strategi ini dilakukan melalui tahap:

1) Pengembangan persil-persil tanah kosong di antara tanah terbangun dengan kegiatan dan intensitas pemanfaatan ruang yang selaras dengan Kawasan TOD; dan

2) Penyesuaian kegiatan atau intensitas pemanfaatan ruang pada tanah terbangun sesuai dengan kriteria teknis kawasan TOD dengan penerapan perangkat penunjang kawasan TOD atau perangkat perwujudan rencana tata ruang lainnya.

Strategi ini tidak menekankan penguasaan tanah oleh satu entitas, namun berkolaborasi dengan pemilik tanah yang ada, yang dapat ditetapkan dalam bentuk ketentuan pemanfaatan ruang dalam rencana tata ruang.

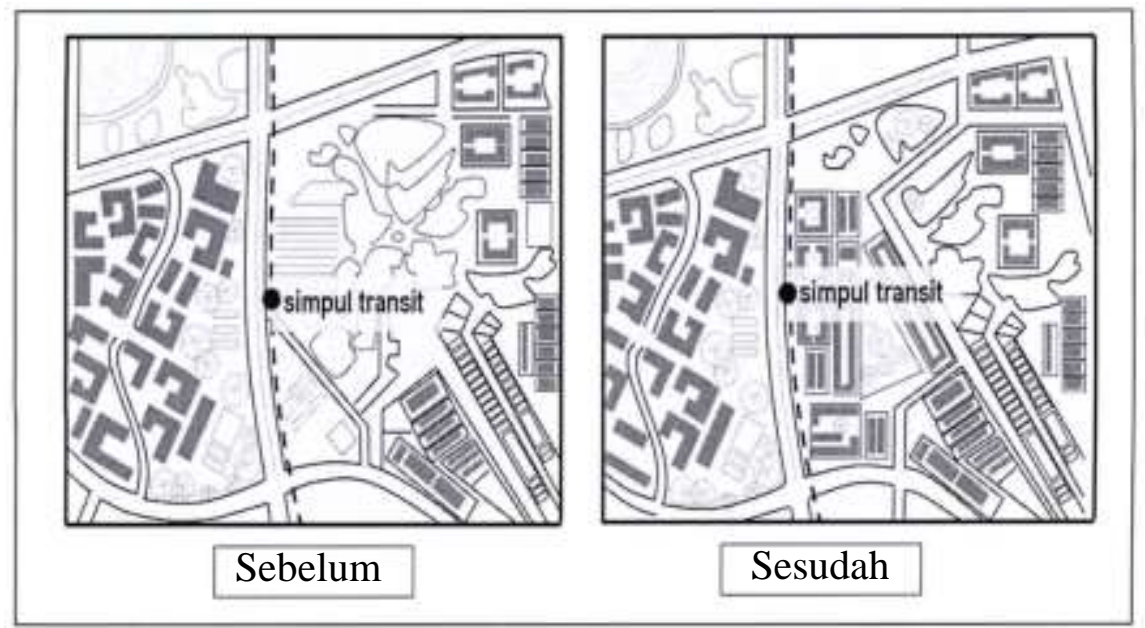

Gambar 2 Pembangunan Tanah Kosong

Sumber: Lampiran Permen ATR BPN No.16 Tahun 2017 tentang Pedoman Pengembangan Kawasan Berorientasi Transit

c. Pembangunan pada kawasan atau tanah yang belum terbangun (new growth area), yaitu pembukaan daerah-daerah baru yang luas dan umumnya terletak di daerah perbatasan pinggir kota (periphery) Strategi ini dilakukan dengan: 
1. Mengembangkan sistem transit/transportasi masal primer/utamanya yang ditunjang dengan sistem sekunder dan feedernya; dan

2. Mengembangkan kawasan di sekitar simpul transit dengan menerapkan perangkatperangkat penunjang perwujudan ruang.

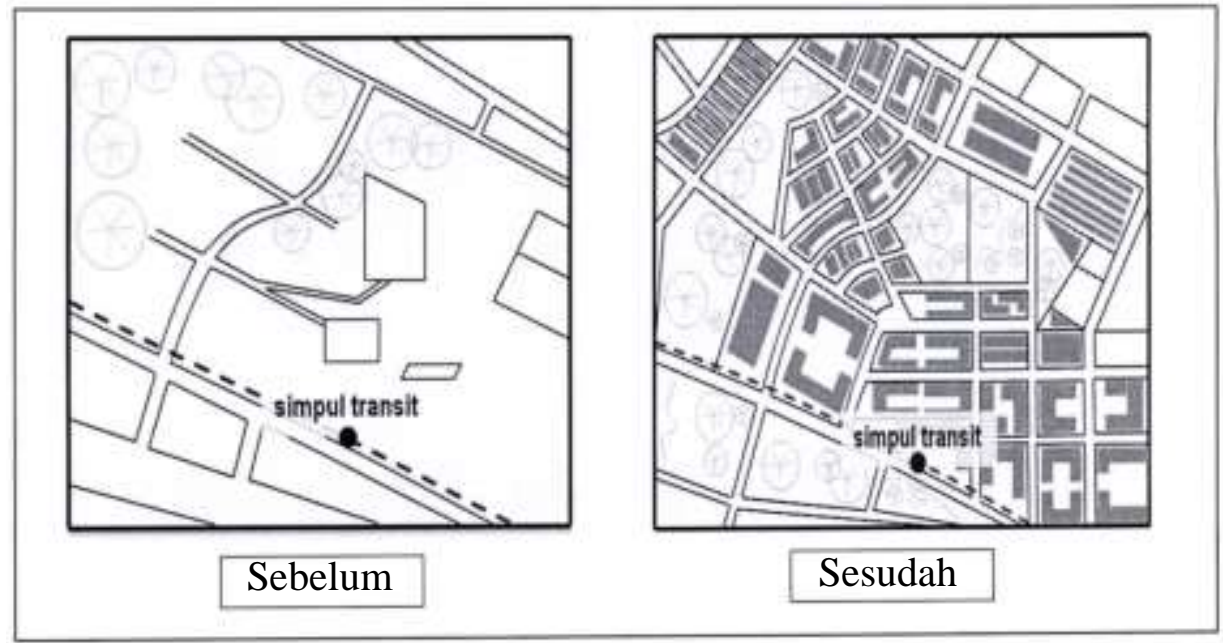

Gambar 0 Pembangunan Tanah yang Belum Terbangun

Sumber: Lampiran Permen ATR BPN No.16 Tahun 2017 tentang Pedoman

Pengembangan Kawasan Berorientasi Transit

Pengembangan kawasan berorientasi transit (TOD) dapat dilakukan oleh masyarakat tanpa mengubah status kepemilikan tanah yang ada dan/atau dikembangkan oleh penyedia layanan angkutan massal berbasis rel sebagai transportasi utama kawasan TOD melalui penguasaan tanah dan pengolaan kawasan sesuai dengan peraturan perundang-undangan.

Transit Oriented Development (TOD) adalah kawasan terpadu dari berbagai kegiatan fungsional kotadengan fungsi penghubung lokal dan antar lokal.

Pengembangan kawasan TOD merupakan salah satu strategi pelaksanaan manajemen kebutuhan lalu lintas. Manajemen kebutuhan lalu lintas dilakukan secara simultan dan terintegrasi melalui strategi:

a. Pengembangan pusat kegiatan pada simpul angkutan umum massal dengan pendekatan perencanaan berskala regional dan/atau kota yang mengutamakan kekompakan dengan penataan kegiatan transit;

b. Perencanaan yang menempatkan sarana lingkungan dengan peruntukan beragam dan campuran;

c. Pengembangan yang mampu memicu/mendorong pembangunan area sekitar pusat transit baik berupa pembangunan penyisipan (infill development), revitalisasi maupun bentuk penataan/perencanaan;

d. Kawasan TOD juga merupakan bagian dari strategi pengembangan kawasan permukiman di mana kawasan tersebut dikembangkan terutama dengan metode konsolidasi lahan guna pembangunan perumahan vertical khususnya rumah susun sederhana;

e. Pembentukan lingkungan yang lebih memprioritaskan kebutuhan pejalan kaki dan pesepeda dengan menyediakan sistem prasarana pedestrian dan sepeda (di mana jalur prioritas akan diatur dalam peraturan gubernur);

f. Pendekatan desain dengan mengutamakan kenyamanan kehidupan pada ruang publik dan pusat lingkungan serta mempertahankan ruang terbuka hijau. 
Terdapat faktor penting dalam penyelenggaraan TOD tersebut yaitu Regulasi yang berkenaan dengan pelaksanaan dan kelembagaan beserta instrumen penunjang lainnya baik teknis maupun non teknis. Peraturan atau regulasi tersebut memiliki kedudukan sebagaimana hirarkinya untuk dapat memberikan koridor yang jelas dalam penyelenggaraan TOD di jabodetabek. Berkenaan dengan regulasi dimaksud, dalam mengembangkan TOD tentunya tidak dalam satu waktu dapat terwujud. Pengembangannya merupakan bagian dari pengembangan wilayah dimana sangat bersifat Long Term dan banyak berkaitan dengan regulasi lainnya. Saat ini terdapat peraturan mengenai TOD khususnya pada kawasan Jabodetabek dengan hirarki yang berbeda-beda dan dalam hal ini BPTJ memiliki peran dalam pengembangan TOD dengan peraturan yang merinci mengenai aspek transportasi dalam pengembangan TOD dimaksud yaitu PERKA BPTJ No. PR.377/AJ.208/BPTJ-2017 tentang pedoman teknis aspek transportasi dalam penyelenggaraan kawasan berorientasi.

Angkutan Umum Massal Di Wilayah Jabodetabek. Namun seiring dengan perkembangannya terdapat beberapa tantangan yang menjadi dasar untuk dapat dilakukan evaluasi maupun penguatan peraturan dimaksud, diantaranya penerapan rekomtek belum secara komprehensif dilakukan bagi seluruh pelaku penyelenggaraan TOD dan belum melekat, proses monitoring dan evaluasi penerapan aspek transportasi pada rekomtek belum dapat dilakukan, dan belum ada dasar hukum mengikat dengan pembangunan seperti IMB yang dapat digunakan untuk mensyaratkan pengembang mengajukan Rekomtek terkait ijin Pembangunan disekitar Kawasan TOD. Dalam pelaksanaannya, tentunya sangat penting untuk menerapkan kebijakan tata ruang yang saling bersinergi dan sinkron dengan kebijakan transportasi. Tetapi sinkronisasi ini tentunya sangat sulit karena kedua sektor tersebut baik di pusat dan di daerah berada di dalam kelembagaan yang berbeda-beda. Oleh karena itu perlu ada skenario kelembagaan agar koordinasi dan sinkronisasi kebijakan ini harus dilakukan. Selain itu adanya insentif dan dis-insentif dalam penerapannya dan hubungannya dengan subsidi di sektor transportasi karena kebijakan TOD ini dapat berjalan apabila ada jaringan angkutan umum massal yang terintegrasi mengakibatkan skenario kelembagaan ini perlu dilakukan.

\section{METODE}

Penelitian yang akan dilakukan dirancang dengan menggunakan metode yuridis normative yang juga dilengkapi dengan teknis pada sisi transportasi. Adapun metode yuridis normatif ini dilaksanakan dengan mengambil data sekunder melalui studi kepustakaan. Data sekunder yang dianalisis dan di evaluasi berupa bahan hukum primer, bahan hukum sekunder, dan bahan hukum tersier. Bahan hukum primer antara lain peraturan yang berkenaan dengan TOD. Bahan hukum sekunder berupa artikel, hasil penelitian hukum dan penelitian lainnya, dan isu yang berkembang berkenaan dengan regulasi yang ada. Sedangkan bahan hukum tersier yang digunakan adalah sumber-sumber terminologi untuk membantu memberikan keterangan tambahan dari bahan hukum primer dan bahan hukum sekunder yang terkait dengan TOD. Untuk menganalisa data sekunder digunakan metode analisis kualitatif dan analisa materi muatan (content analys). Metode penulisannya menggunakan deskriptif analitis.

\section{HASIL DAN PEMBAHASAN}

Adapun hasil Analisa dirangkum dalam tabel dibawah ini dengan ketentuan-ketentuan yuridis dan teknis transportasi. Dalam hal ini penelitian dilakukan dengan bersumber pada data-data sekunder yang kemudian dikomparasikan dan selanjutnya aspek-aspek transportasi dalam kawasan TOD dihimpun untuk kemudian diperjelas sebagaimana dasar-dasar dari berbagai regulasi terkait. 


\section{Tabel 1. Peningkatan Aspek-Aspek Transportasi Dalam Penguatan Peraturan TOD} Berdasarkan Rujukan Regulasi Terkait

\begin{tabular}{|c|c|c|c|c|c|}
\hline$\overline{\mathrm{No}}$ & Variabel & Indikator & Definisi & Nilai / Ukuran / Jumlah & Dasar Rujukan Hukum \\
\hline \multirow[t]{6}{*}{$\overline{1}$} & \multirow[t]{6}{*}{$\begin{array}{l}\text { Aspek } \\
\text { Keterhu- } \\
\text { bungan / } \\
\text { Konektivi } \\
\text {-tas }\end{array}$} & \multirow[t]{2}{*}{$\begin{array}{l}\text { Jalur } \\
\text { Penghubung }\end{array}$} & $\begin{array}{l}\text { Penyeberangan } \\
\text { Sebidang }\end{array}$ & $\begin{array}{l}\text { Tersedia dan sesuai dengan standar } \\
\text { teknis }\end{array}$ & \multirow{2}{*}{$\begin{array}{l}\text { - Peraturan Menteri Pekerjaar } \\
\text { Umum Nomo } \\
\text { 03/PRT/M/2014 tentang } \\
\text { Pedoman Perencanaan } \\
\text { Penyediaan dan Pemanfaatar } \\
\text { Prasarana dan Saran } \\
\text { Jaringan Pejalan kaki d } \\
\text { Kawasan Perkotaan } \\
\text { - Surat Edaran Menter } \\
\text { Pekerjaan Umum dar } \\
\text { Penataan Ruang Nomo } \\
\text { 02/SE/M/2018 tentang } \\
\text { Pedoman Pd 03 - 2017- } \\
\text { Perencanaan teknis fasilita } \\
\text { pejalan kaki } \\
\text { - Standar No. 027/T/Bt/1995 } \\
\text { tentang Tata cara } \\
\text { perencanaan jembatar } \\
\text { penyeberangan untuk pejalar } \\
\text { kaki di kawasan perkotaan }\end{array}$} \\
\hline & & & $\begin{array}{l}\text { Penyeberangan } \\
\text { Tidak Sebidang }\end{array}$ & $\begin{array}{l}\text { Tersedia dan sesuai dengan standar } \\
\text { teknis jika Volume Pejalan kaki > } \\
\text { 1100/jam dan volume kendaraan }> \\
\text { 750/jam }\end{array}$ & \\
\hline & & $\begin{array}{l}\text { Prioritas } \\
\text { Persimpang } \\
\text { an }\end{array}$ & $\begin{array}{l}\text { Pengukuran yang } \\
\text { menilai rasio } \\
\text { persimpangan yang } \\
\text { memprioritaskan } \\
\text { Jalur Pejalan kaki }\end{array}$ & $\begin{array}{l}\text { Rasio } \\
=\frac{\sum \text { simpang jalur pejalan kaki }}{\sum \text { simpang kendaraan bermotor }}\end{array}$ & TOD STANDART, ITDP \\
\hline & & $\begin{array}{l}\text { Shortest } \\
\text { Distance } \\
\text { Connection }\end{array}$ & $\begin{array}{l}\text { Jarak terdekat } \\
\text { yang dapat } \\
\text { dihubungkan }\end{array}$ & $\begin{array}{l}\text { Rasio } \\
=\frac{\text { jarak lurus dua titik terhubung }}{\text { jarak aktual fasilitas penghubung }}\end{array}$ & TOD STANDART, ITDP \\
\hline & & $\begin{array}{l}\text { Rambu } \\
\text { Informasi }\end{array}$ & $\begin{array}{l}\text { Rambu yang } \\
\text { mengarahkan } \\
\text { fasilitas } \\
\text { penghubung }\end{array}$ & $\begin{array}{l}\text { Tersedia dan sesuai dengan standar } \\
\text { teknis }\end{array}$ & $\begin{array}{l}\text { Peraturan Menteri Perhubungan } \\
\text { Nomor PM } 13 \text { Tahun } 2014 \\
\text { tentang Rambu Lalu Lintas }\end{array}$ \\
\hline & & $\begin{array}{l}\text { Pagar } \\
\text { Pengaman }\end{array}$ & Ketersediaan & $\begin{array}{l}\text { Tersedia dan sesuai dengan standar } \\
\text { teknis }\end{array}$ & $\begin{array}{l}\text { Peraturan Menteri Perhubungan } \\
\text { Nomor PM } 82 \text { Tahun } 2018 \\
\text { tentang Alat Pengendali dan } \\
\text { Pengaman Pengguna Jalan }\end{array}$ \\
\hline \multirow[t]{3}{*}{2} & \multirow[t]{3}{*}{$\begin{array}{l}\text { Aspek } \\
\text { Angkutan } \\
\text { Umum }\end{array}$} & $\begin{array}{l}\text { Frekuensi } \\
\text { Pelayanan }\end{array}$ & $\begin{array}{l}\text { Merupakan } \\
\text { Frekuensi } \\
\text { pelayanan } \\
\text { angkutan umum } \\
\text { di suatu kawasan }\end{array}$ & $\begin{array}{l}\text { TOD Kota }=<5 \text { menit } \\
\text { TOD Sub Kota }=<5-15 \text { Menit } \\
\text { TOD Lingkugan }=15-30 \text { Menit }\end{array}$ & \multirow[t]{3}{*}{$\begin{array}{l}\text { Perka BPTJ no } \\
\text { 377/AJ.208/BPTJ-2017 }\end{array}$} \\
\hline & & $\begin{array}{l}\text { Jam Operasi } \\
\text { Pelayanan }\end{array}$ & $\begin{array}{l}\text { Merupakan jam } \\
\text { operasi pelayanan } \\
\text { angkutan umum } \\
\text { di suatu kawasan }\end{array}$ & $\begin{array}{l}\text { TOD Kota }=\geq 12 \text { jam } \\
\text { TOD Sub Kota }=\geq 10 \text { jam } \\
\text { TOD Lingkugan }=\geq 8 \text { jam }\end{array}$ & \\
\hline & & $\begin{array}{l}\text { Jumlah } \\
\text { Minimal } \\
\text { SAUM }\end{array}$ & $\begin{array}{l}\text { Merupakan } \\
\text { jumlah minimal } \\
\text { keberadaan } \\
\text { SAUM di Kawasn } \\
\text { TOD }\end{array}$ & $\begin{array}{l}\text { Minimal terdapat } 1 \text { Moda Rapid } \\
\text { dan } 1 \text { Moda Feeder }\end{array}$ & \\
\hline \multirow[t]{2}{*}{3} & \multirow[t]{2}{*}{$\begin{array}{l}\text { Pejalan } \\
\text { Kaki }\end{array}$} & $\begin{array}{l}\text { Rasio Jalur } \\
\text { Pejalan } \\
\text { Kaki }\end{array}$ & $\begin{array}{l}\text { Perbandingan } \\
\text { Panjang total Jalur } \\
\text { pejalan kaki } \\
\text { dengan jalur } \\
\text { kendaraan } \\
\text { bermotor }\end{array}$ & $\begin{array}{l}\text { Rasio } \\
=\frac{\sum \text { total jalur pejalan kaki }}{\sum \text { total jalur kendaraan bermo } 1}\end{array}$ & TOD STANDART, ITDP \\
\hline & & $\begin{array}{l}\text { Trotoar / } \\
\text { Jalur } \\
\text { Pejalan } \\
\text { Kaki }\end{array}$ & $\begin{array}{l}\text { Indikator yang } \\
\text { mempengaruhi } \\
\text { Jalur Pejalan Kaki }\end{array}$ & $\begin{array}{ll}\text { - } & \text { Lebar Trotoar } \\
\text { - } & \text { Kemiringan Memanjang dan } \\
& \text { Melintang } \\
\text { - } & \text { Pelandaian } \\
\text { - } & \text { Pengaturan Jalan Masuk }\end{array}$ & $\begin{array}{l}\text { Peraturan Menteri } \\
\text { Pekerjaan Umum Nomor } \\
\text { 03/PRT/M/2014 tentang } \\
\text { Pedoman Perencanaan, } \\
\text { Penyediaan dan }\end{array}$ \\
\hline
\end{tabular}




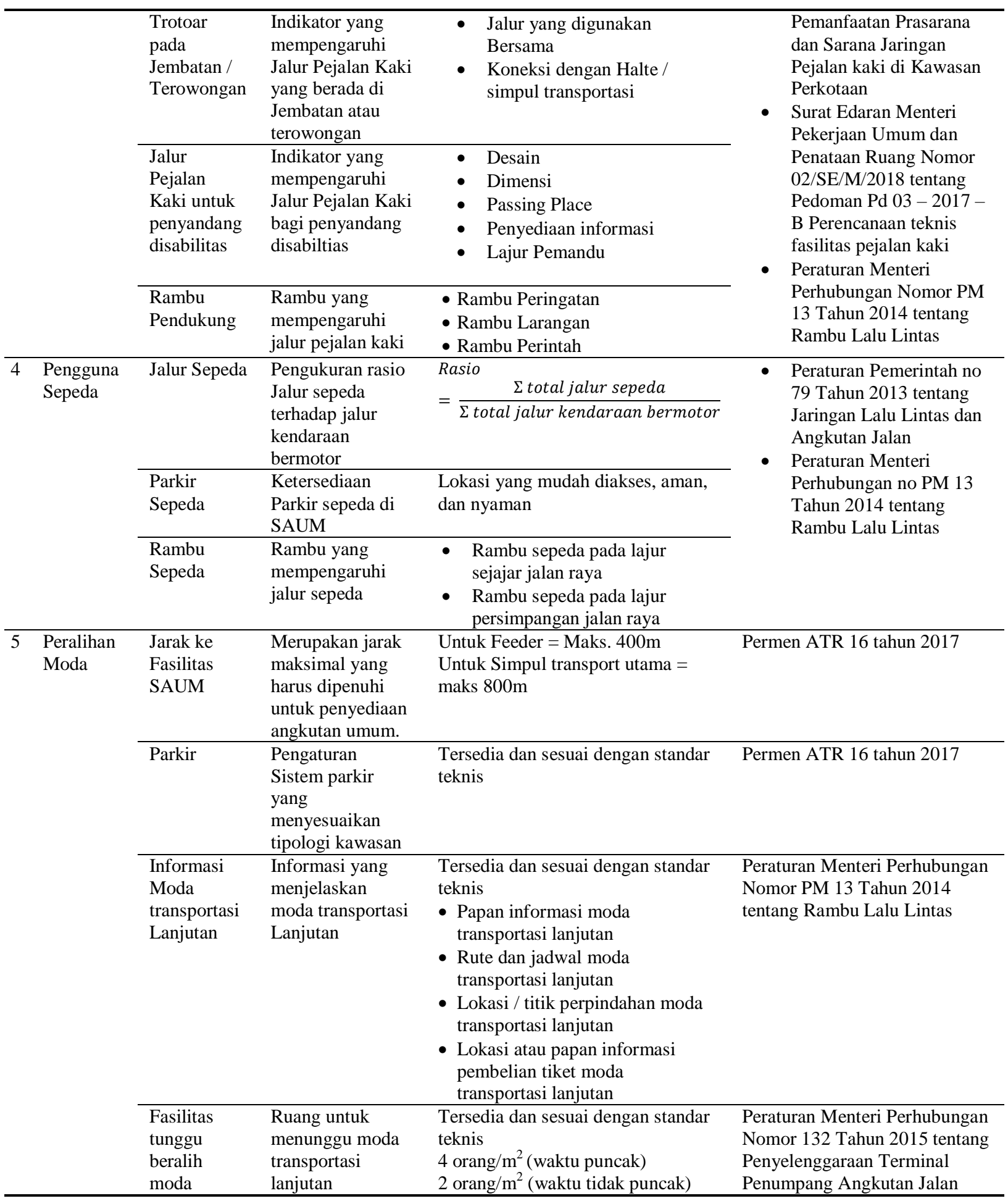

Keterkaitan Peraturan terhadap isu yang berkembang: (1)Banyak pengembang hanya memainkan status TOD sebagai gimmick marketing dalam offering product kepada masyarakat. (2)Pengembang dapat langsung mendirikan Kawasan TOD tanpa perlu perka BPTJ terlebih pada Kawasan milik sendiri (tidak ada engagement thd penyelenggaraan Kawasan TOD). (3)Ego sectoral kerap menjadi masalah utama dalam proses sinkronisasi kebijakan. (4)Kemudahan dan kejelasan hukum dalam mengikat penyelenggaraan TOD baik dari segi prosedur perijinan maupun pengawasan. Harmonisasi perka BPTJ terhadap peraturan TOD lainnya. Isi perka BPTJ berkenaan dengan sustainable development. 
Adapun peran penguatan regulasi untuk aspek transportasi pada penyelenggaraan TOD Jabodetabek meliputi penerapan mekanisme LVC yang diperkuat dengan penerapan Bentuk insentif dan disinsentif, disisi ain penguatan Kelembagaan sebagai dukungan terhadap kebijakan regulator khususnya berkenaan dengan kemudahan berinvestasi dan dalam hal ini perlu peningkatan SOP pengajuan / permohonan rekomtek serta bentuk pembinaan / pengawasan atas staging pelaksanaan penyelenggaraan TOD

\section{SIMPULAN}

Aspek transportasi menjadi penting untuk bukan hanya sekedar ada, akan tetapi juga harus menggambarkan sesuai demand perjalanan dan berkelanjutan. Untuk menjaga keberlanggsungan aspek transportasi dalam pengembangan TOD, maka Peraturan kepala BPTJ terkait TOD ini harus masuk didalam rekomendasi analisa dampak lalulintas khusus pengembangan kawasan TOD. Struktur kota yang sudah terbentuk sangat mempengaruhi penerapan konsep TOD seperti persebaran permukiman yang tidak teratur sehingga kawasan permukiman dan simpul transportasi tidak terkoneksi. Di Jabodetabek konsep TOD mulai banyak terlihat namun tidak didukung dengan perencanaan yang komprehensif sehingga belum mampu mengintegrasikan berbagai fasilitas yang ada di dalamnya.

\section{DAFTAR PUSTAKA}

Kementerian Perhubungan. (2018). Peraturan Presiden Nomor 55 tahun 2018 tentang Rencana Induk Transportasi Jabodetabek.

Kementerian ATR, (2017). Peraturan Menteri ATR Nomor 16 Tahun 2017 tentang PedomanPengembangan Kawasan Berorientasi Transit.

Ircham., Munawar, Ahmad., Mutohar, Imam. (2014). Peran Kebijakan Transportasi UntukMendukung Aksesibilitas dan Mobilitas Pada Pengembangan Wilayah Perkotaan. The 17th FSTPT International Symposium, Jember.

Muchlisin., Munawar, Ahmad., and Samuel, P. S. (2013). The Role Of New Transport Policy On Creating Sustainable And Integrated Public Transit System In JakartA (Case Studi : Transjakarta, Indonesia And Freiburg, Germany).

Kementerian Perhubungan. (2009). Undang-Undang No 22 Tahun 2009 tentang Lalu Lintas dan Angkutan Jalan (LLAJ).

Susilo, Yusak, O., Joewono, basuki, Tri., Santosa, Wimpy., and Parikesit, Danang. (2007). A Reflection Of Motorization And Pulic Journal Of The Easters Asia Society For Transport In Jakarta Metropolitan Area Transportation Studies, Vol. 7

Alonso. (2002). The Benefits Of Building Barrier-Free: A Contingent Valuation Of Accessibility As An Attribute Of Housing. European Journal of Housing Policy 2(1), 2002, 25-44

Bernick and Cervero. (1997). Transit Villages In The 21st Century. New york, United States : McGraw-Hill, Incorporated.

Cervero. (1992). Land Market Impacts of Urban Rail Transit and Joint Development : An Empirical Study of Rail Transit in Washington, DC and Atlanta. Working Paper UCTC No. 135. University of California, Berkeley. 